\title{
ARTICLE
}

\section{Double blind, two dose, randomized, placebo-controlled, cross-over clinical trial of the positive allosteric modulator at the alpha7 nicotinic cholinergic receptor AVL-3288 in schizophrenia patients}

Joshua T. Kantrowitz ${ }^{1,2,3}$, Daniel C. Javitt ${ }^{1,2,3}$, Robert Freedman (D) $^{4}$, Pejman Sehatpour ${ }^{1,2,3}$, Lawrence S. Kegeles ${ }^{1,2}$, Marlene Carlson ${ }^{1,2}$, Tarek Sobeih $^{3}$, Melanie M. Wall ${ }^{1,2}$, Tse-Hwei Choo ${ }^{1,2}$, Blair Vail ${ }^{2}$, Jack Grinband ${ }^{1,2}$ and Jeffrey A. Lieberman ${ }^{1,2}$

Despite their theoretical rationale, nicotinic alpha-7 acetylcholine $\left(\mathrm{na}_{7}\right)$ receptor agonists, have largely failed to demonstrate efficacy in placebo-controlled trials in schizophrenia. AVL-3288 is a $\mathrm{na}_{7}$ positive allosteric modulator (PAM), which is only active in the presence of the endogenous ligand (acetylcholine), and thus theoretically less likely to cause receptor desensitization. We evaluated the efficacy of AVL-3288 in a Phase 1b, randomized, double-blind, placebo-controlled, triple cross-over study. Twenty-four non-smoking, medicated, outpatients with schizophrenia or schizoaffective disorder and a Repeatable Battery for the Assessment of Neuropsychological Status (RBANS) $\geq 62$ were randomized. Each subject received 5 days of AVL-3288 (10, 30 mg) and placebo across three separate treatment weeks. The primary outcome measure was the RBANS total scale score, with auditory P50 evoked potential suppression the key target engagement biomarker. Secondary outcome measures include task-based fMRI (RISE task), mismatch negativity, the Scale for the Assessment of Negative Symptoms of Schizophrenia (SANS) and the Brief Psychiatric Rating Scale (BPRS). Twenty-four subjects were randomized and treated without any clinically significant treatment emergent adverse effects. Baseline RBANS ( $82 \pm 17)$ and BPRS ( $41 \pm 13)$ scores were consistent with moderate impairment. Primary outcomes were negative, with nonsignificant worsening for both active groups vs. placebo in the P50 and minimal between group changes on the RBANS. In conclusion, the results did not indicate efficacy of the compound, consistent with most prior results for the na target.

Neuropsychopharmacology (2020) 45:1339-1345; https://doi.org/10.1038/s41386-020-0628-9

\section{INTRODUCTION}

Schizophrenia is a major public health problem associated with positive and negative symptoms [1], along with cognitive deficits $[2-4]$ that represent a core feature of the disorder $[5,6]$ and are highly predictive of functional outcomes $[7,8]$. All FDA approved antipsychotic drugs for schizophrenia act primarily by blocking dopamine $D_{2}$ receptors [9]. While generally effective for positive symptoms, antipsychotics have minimal efficacy for cognitive and negative symptoms, indicating the need for alternative treatments $[1,10,11]$

Based on observations of the high rate of nicotine (tobacco) use in schizophrenia $[12,13]$, study of nicotinic alpha-7 acetylcholine $\left(n a_{7}\right)$ receptors has been proposed as a potential target for drug development [14]. As recently reviewed $[15,16]$, activation of na receptors can modulate both the glutamate [17] and dopaminergic $[18,19]$ systems. The $\mathrm{na}_{7}$ receptor is localized on gammaaminobutyric acid (GABA)-ergic interneurons, and its activation allows for the release of GABA, which activates presynaptic inhibitory $G_{A B A}$ receptors on the excitatory inputs to the glutamatergic pyramidal cells.

While the focus of clinical trials of $\mathrm{na}_{7}$ agonists in schizophrenia have primarily been on cognition, trials have also evaluated efficacy on negative symptoms. The results of $\mathrm{na}_{7}$ targeted trials have been variable at best to date, suggesting either limitations in the experimental compounds or the therapeutic viability of the target. In general, initial Phase II studies of several, but not all $\mathrm{na}_{7}$ agonists, including DMXB-A [20], JNJ-39393406 [21], EVP-6124 [22], TC-5619 [23], ABT-126 [24], and RG3487 [25] tended to show statistically significant, but small effect size improvements on cognitive and negative symptoms that did not replicate in larger follow-ups [26-28].

An ongoing issue with $\mathrm{na}_{7}$ receptor agonist development is that the $\mathrm{na}_{7}$ receptor quickly desensitizes in the presence of agonists [26]. A possible solution to this is the use of positive allosteric modulators (PAMs) of the $a_{7}$ receptor, which are only active in the presence of acetylcholine and thus less likely to cause desensitization [29]. AVL-3288, a "first in class", selective, na ${ }_{7}$ receptor PAM was recently tested in a single-dose Phase 1a study in healthy controls [30], finding non-significant, but moderate effect size acute improvements in cognition $(d=0.49)$ in the 10 and $30 \mathrm{mg}$ non-smoking cohorts.

The present report is both the first study of AVL-3288 in schizophrenia and the first multi-dose assessment of target engagement, hypothesizing greater improvements in at least

\footnotetext{
${ }^{1}$ Columbia University, New York, USA; ${ }^{2}$ New York State Psychiatric Institute, New York, USA; ${ }^{3}$ Nathan Kline Institute, Orangeburg, USA and ${ }^{4}$ U Colorado, Denver, CO, USA Correspondence: Joshua T. Kantrowitz (jk3380@cumc.columbia.edu)

ClinicalTrials.gov Identifier: NCT02978599
}

Received: 3 November 2019 Revised: 6 January 2020 Accepted: 26 January 2020

Published online: 3 February 2020 
one AVL-3288 dose vs. placebo. To avoid interactions with nicotine, we only enrolled nonsmokers. We conducted this study using the NIMH Fast-Fail approach [31-33], which supports conducting target engagement studies to assess whether the experimental agent is present in the brain and binding its molecular target in adequate concentrations to exert therapeutic effects. As previously reviewed [32, 34], the use of pre-specified target engagement biomarkers in early stage trials can help determine both the therapeutic viability of the experimental compounds and dose range prior to larger Phase II studies. In particular, the Fast-Fail approach suggests failing a compound if adequate target engagement is not reached.

As in previous $\mathrm{na}_{7}$ agonist trials $[20,30]$, we utilized the Repeatable Battery for the Assessment of Neuropsychological Status (RBANS) [35] and P50 [36] as the primary biomarkers. Secondary outcomes included the Brief Psychiatric Rating Scale (BPRS) [37], the scale for the assessment of negative symptoms (SANS) [38], the relational and item specific encoding ("RISE") task $[39,40]$ and in a subsample, mismatch negativity (MMN).

In the P50, sensory gating is assessed based on the auditoryevoked response to the second stimuli of a paired stimuli paradigm [36]. In healthy controls, the second (test) stimuli generates a P50 wave with less than half the amplitude of the initial or conditioning stimuli, but in schizophrenia, there is significantly less inhibition of the test response [36]. While P50 is not a direct measure of $\mathrm{na}_{7}$ target engagement, there is an extensive literature linking $\mathrm{na}_{7}$ receptor function to P50 gating $[41,42]$, including positive genetic linkages for the $15 q 13$ eq14 region for both schizophrenia and P50 sensory gating deficits [43]. The RISE task has not been used in previous $\mathrm{na}_{7}$ trials but is a well validated and known to engage dorsolateral prefrontal cortex (DLPFC) and hippocampal regions involved in long term memory. Schizophrenia patients show reduced DLPFC BOLD activation [44], suggesting potential biomarker utility of the task.

In the present project, two doses of AVL-3288 (10 and $30 \mathrm{mg}$ ) were chosen based on preliminary evidence of efficacy and safety in the single-dose Phase 1a study [30]. Each treatment-phase involved five consecutive days of the study drug (at either 10 or $30 \mathrm{mg}$ ) or placebo followed by a 16-day washout period. The drug was fully eliminated at 4 days in the Phase 1a study [30], and a 5 day exposure was used for each dose to provide additional safety and efficacy information to inform possible Phase 2 studies of longer duration.

\section{MATERIALS AND METHODS}

Subjects

This was a Phase $1 \mathrm{~b}$, randomized, placebo-controlled, doubleblind, cross-over investigation conducted at Columbia University Medical Center/New York State Psychiatric Institute (CUMC/NYSPI). The study was approved by the New York State Psychiatric Institute Institutional Review Board, and conducted between January 2017 and November 2018. Written informed consent was obtained from all participants prior to participation. The trial protocol can be found in Supplement 1.

Enrollment criteria included male and female subjects diagnosed with schizophrenia or schizoaffective disorder, aged 18-50, nonsmoking (serum cotinine $<20$ ), medically stable, RBANS $\geq 62$, stable dose of antipsychotic medication other than clozapine for at least 4 weeks, lack of participation in study of investigational medication/ device within 4 weeks. The RBANS lower limit was set at $>1 \%$ of the initial standardization sample [45] to allow for a capacity to learn, and changed from $\geq 65$ (upper limit of the $1 \%$ range) to $\geq 62$ (lower limit of the $1 \%$ range) midway through the study.

\section{Design}

After providing informed consent, and medical/psychiatric screening to confirm eligibility, subjects underwent a screening RBANS.
Each subject completed each of the three treatment-phases in a double-blind, randomized order. Each treatment-phase involved five consecutive days of either AVL-3288 (10 or $30 \mathrm{mg}$ ) or placebo followed by a 16-day washout period. Each study drug treatment was taken in the clinic. Non-smoking status was verified by cotinine tests at screening and each treatment week. A randomization list was produced by the study biostatistician.

\section{Behavioral assessments}

The primary outcome measure was the RBANS total scale score, conducted 45 min post dose on day five of each treatment week, with subscales secondary. To minimize practice effects, four versions of the RBANS were used for the four assessments. Symptoms were assessed with the BPRS and SANS on the 4th day of treatment, after the MRI.

\section{Electrophysiology}

P50 inhibition was conducted with previously described methods [30] on the fifth day of each treatment, beginning immediately after the RBANS. MMN was collected in a subsample $(n=6)$ [46].

\section{RISE task methods}

Task-based fMRI was conducted on the fourth day of each treatment phase. The RISE task was implemented in accordance with [44]. Briefly, subjects viewed a series of visual depictions of objects that were presented in pairs on a presentation screen within the MRI scanner. Examples included pictures of animals (e.g., owl, snail) or inanimate objects (e.g., apple, pail). fMRI data was collected during one encoding phase and two retrieval phases. During the encoding phase, subjects viewed pairs of objects and alternated between performing an item-specific encoding task (e.g., Is either object living?) and a relational encoding task (e.g., Can one object fit inside the other?). During an item recognition phase, subjects viewed pairs of items that were either previously presented or previously unstudied (50\% each) and indicated whether they were new or old. During an associative recognition phase, subjects indicate whether the two items had previously been presented together.

In all phases, trials were presented for $3 \mathrm{~s}$ each with a $0-10 \mathrm{~s}$ jittered intertrial interval. BOLD data were analyzed using multiple linear regression implemented in fMRI Expert Analysis Tool. For this task, the primary outcome measures included behavioral performance and DLPFC BOLD activation on the item and associative recognition task.

Pharmacokinetics

Steady state and washout-phase pharmacokinetics (PK) were conducted as described in [30], with AVL-3288 plasma level assessed at $4 \mathrm{~h}$ post dose on day 4 of each treatment week, and during the washout phase, at least 8 days after last dose.

\section{Power analysis}

The study was powered on the RBANS total effects in the Phase 1a study [30]. There were eight subjects per dose cohort in this study. The power analysis assumed a moderate within subject correlation of 0.33 between the RBANS assessments, and the sample size of 24 had ample capability to tolerate drop-outs, with only 13 subjects needed for a minimal power of 0.8 (1-beta at alpha -0.052 tails). The aim of the study was to determine if there is an effect of AVL-3288 in patients with schizophrenia at any dose vs. placebo. Therefore, there was no correction for multiple doses or a planned between dose comparison.

\section{Statistical analysis}

Demographics and outcomes at baseline were summarized for the overall sample using means and SDs for continuous variables, and proportions and frequencies for categorical variables.

The effect of AVL-3288 on the main outcomes of cognition, symptoms, and neurophysiological measures were assessed using 
repeated measures linear regression models, featuring an $A R(1)$ correlation structure to account for within-subject correlations, with the change from baseline of the outcome measure, for all of the three post-treatment assessments, as the response variable. Treatment was the predictor of interest, with time and the baseline value of the outcome as covariates. This model was fit for each of the outcomes: BPRS (total and subscales), SANS (total and subscales), RBANS (total and subscales), P50, and MMN. Since there was no baseline assessment for the RISE task outcomes, similar models were fit, except that the response variable was the absolute score, and the baseline covariate was omitted. Contrasts from the models were used to estimate the change from baseline for each treatment, and the pairwise differences between treatment and placebo. Models were also fit to assess the effects of time, treatment order, and for the RBANS outcomes, test version.

Additionally, Spearman's correlation coefficients were calculated to assess the relationship between study outcomes, for each of the three post-treatment assessments. Descriptive statistics were produced for adverse events and for drug concentrations in blood sample. All analyses were performed using SAS version 9.4. Values in text are Mean \pm SD.

\section{RESULTS}

Sample

Twenty-four subjects (Fig. 1; Table 1) were randomized and included in the safety analysis. Baseline RBANS ( $82 \pm 17)$ and BPRS $(41 \pm 13)$ scores were consistent with moderate baseline impairment. Nineteen subjects completed all three phases, with two additional subjects completing Treatment week 3 assessments after stopping study drug mid treatment-phase.

Symptom and cognition effects

AVL-3288 treatment was not associated with any significant between-group improvements in the RBANS total for the either the $10 \mathrm{mg}\left(t_{41}=0.24, p=0.81, d=-0.04\right)$ or $30 \mathrm{mg}$ dose $\left(t_{41}=\right.$ $0.32, p=0.75, d=0.05$ ) vs. placebo (Table 2). There was no significant order effect $\left(F_{5,18}=0.68, p=0.65\right)$. Change in RBANS subscale scores were also non-significant. A non-significant, moderate effect size in the delayed memory domain favoring the $30 \mathrm{mg}$ dose was seen $(d=0.33$, Table 2$)$. Significant improvement for the $10 \mathrm{mg}$ group vs. placebo $\left(t_{37}=2.3, p=\right.$ $0.03, d=0.33$ ) was seen for the SANS attention subscale, but there were no other significant between group changes in the other SANS or BPRS outcomes (Table 2).

\section{Neurophysiological measures}

EEG. All three groups exhibited significant within group P50 suppression, but there were no significant between-group improvements for the $10 \mathrm{mg}\left(t_{40}=0.88, p=0.38, d=-0.10\right)$ or $30 \mathrm{mg}$ dose $\left(t_{40}=0.2, p=0.23, d=-0.13\right)$ vs. placebo (Table 2 ). There was no significant order effect $\left(F_{5,18}=0.25, p=0.93\right)$. MMN was collected in a subsample (Table 2), finding significant worsening for the $10 \mathrm{mg}$ group vs. placebo $\left(t_{5}=2.7, p=0.04, d=\right.$ -0.84 ) for MMN to frequency deviants.

MRI. Due to technical issues, the RISE task was not completed in all subjects. 18, 18, and 19 subjects were included in the $10 \mathrm{mg}, 30$ $\mathrm{mg}$, and placebo groups, respectively. There were no significant between group differences in behavioral change in item recognition or association following encoding for either dose, nor were there any significant between-group changes in BOLD (Table 2). A non-significant, small-moderate effect size advantage for the 30 $\mathrm{mg}$ dose was seen for BOLD during the recognition task $(d=0.30)$.

Pharmacokinetics

AVL-3288 levels were assessed per schedule (Table 3), and treatment phase levels were consistent with Phase 1a studies [30].
Unexpectedly, the 5-day treatment led to accumulation in drug levels, leading to detectable drug levels during the washout and placebo phase for treatment periods 2 and 3 .

\section{Confounding factors}

Several post hoc analysis were conducted to control for the unexpected drug accumulation. Results remained non-significant in a per protocol sample of completers, analysis of treatment phase 1 only, and after control for drug level (not reported).

\section{Correlational analysis}

There were no significant correlations between primary biomarkers and clinical outcomes within the active groups.

\section{Safety measures}

No clinically significant side effects were observed. Five patients were withdrawn, three for unrelated lab abnormalities, one for positive cotinine test, and one for withdrawn consent. Nausea, somnolence, headache, dizziness and urinary urgency were the only side effects reported in more than $5 \%$ in the active groups (Table 4).

\section{DISCUSSION}

AVL-3288 was well tolerated at all doses but did not significantly affect the primary target engagement (P50) or cognitive (RBANS) outcomes at any of the tested doses. The lack of effects on the measures of target engagement is consistent with a lack of clinical effect, and with negative meta-analysis of prior $\mathrm{na}_{7}$ receptor agonist studies in schizophrenia [14]. Although our results are negative, this study demonstrates the utility of the NIMH Fast-Fail approach [31-33].

P50 was used as the primary measure of target engagement due to studies suggesting impairment in schizophrenia and relationship with $\mathrm{na}_{7}$ receptor agonist function [47]. Additionally, P50 may be normalized by clozapine treatment [48], suggesting potential clinical relevance. In the present report, P50 showed non-significant, reduced suppression vs. placebo, while MMN significantly worsened. Thus, to the extent that auditory biomarker changes were observed, they were in the direction of worsening. Similarly, there were no significant between group changes in the RISE task. Prior $\mathrm{na}_{7}$ receptor agonist studies have shown varied effects on P50 and other auditory biomarkers such as MMN [17, 20, 21, 30]. In contrast to studies of glutamatergic treatments [49-52], auditory biomarker changes in $\mathrm{na}_{7}$ receptor agonist studies may have a less clear relationship to clinical or cognitive improvement.

Several limitations of the present study should be acknowledged. First, our design of three five-day treatments restricted our assessments to subchronic changes. While it is possible that a longer duration of treatment would lead to improvements, the lack of target engagement argues against this. Second, although the crossover design limited the number of patients who were exposed to an investigational drug with unknown benefit, this design increases the potential for carryover effects from repeated treatment and practice from testing exposure. In particular, we saw an unexpected accumulation in drug levels leading to detectable levels across all groups, including placebo. Nevertheless, we do not feel that this meaningfully impacted the results, as there was not a significant order effect or a change in results after controlling for AVL-3288 level. Moreover, we did not see any indication of a drug effect in Treatment Phase 1, i.e., prior to accumulation of drug. The RBANS exhibited limited practice effects in a previous, similar study [20]. In our statistical analysis, we used a general linear model that accounts for both order (practice) effects and intersubject variance to analyze treatment effects.

Third, while studies have shown positive $P 50$ results $[17,20]$, not all $[21,30]$ previous na7 studies have shown significant P50 effects 


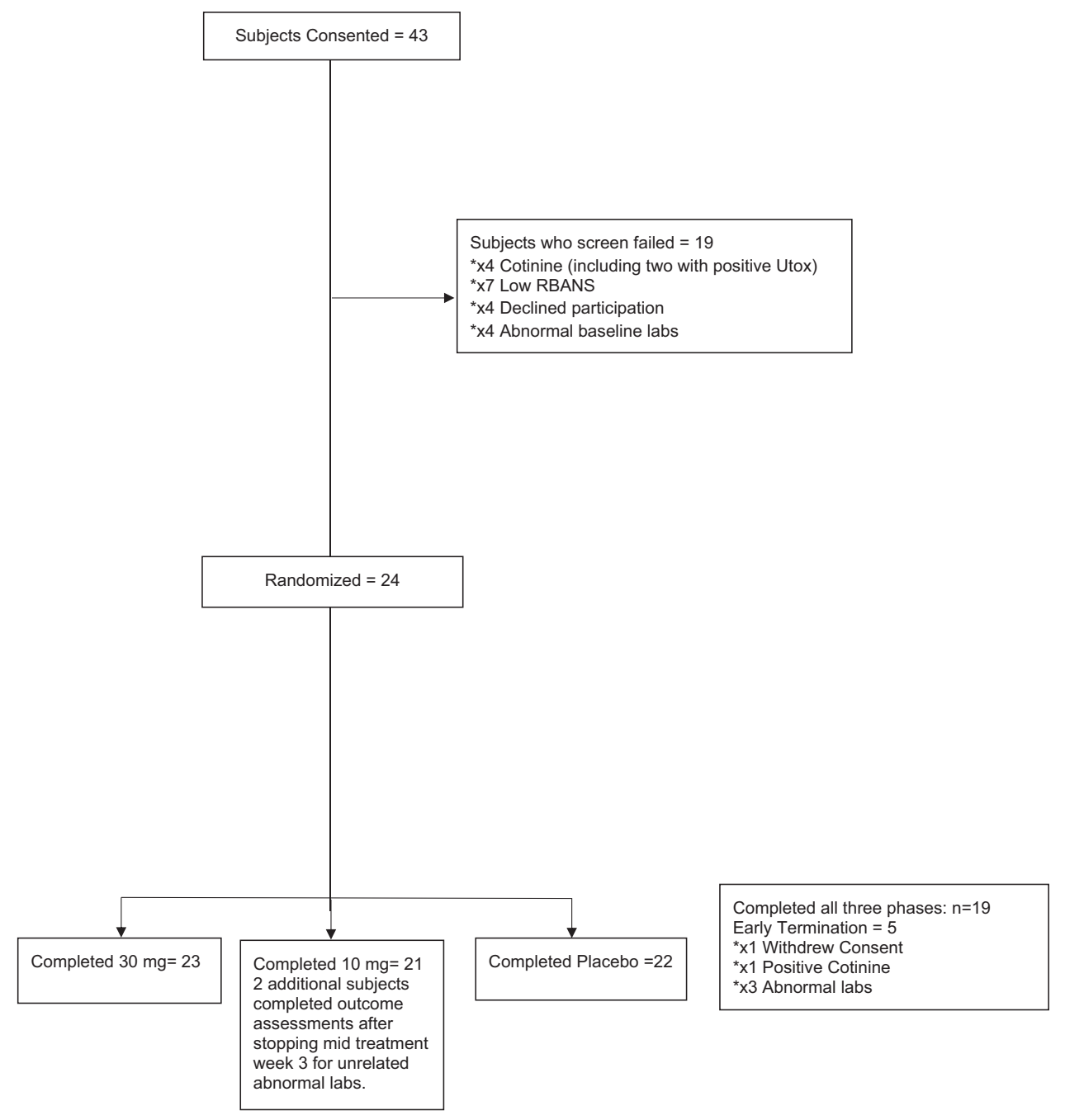

Fig. 1 Consort chart.

Table 1. Demographics and baseline characteristics.

Age $($ Mean \pm SD)

$35.6 \pm 7.1$

Male \%

High school graduate (\%)

Completed $30 \mathrm{mg}$ phase $(n)$

Completed $10 \mathrm{mg}$ phase $(n)$

Completed placebo phase $(n)$

$83.3 \%$

$75 \%$

23

$21^{\mathrm{a}}$

22

BPRS (Mean \pm SD)

$39.5 \pm 12.6$

SANS (Mean \pm SD)

$39.1 \pm 17.3$

RBANS total (Mean \pm SD)

$81.3 \pm 15.7$

P50 ratio

$1.3 \pm 1.1$

${ }^{a}$ Two additional subjects completed outcome assessments after stopping mid treatment week 3 for unrelated abnormal labs.

of $\mathrm{na}_{7}$ receptor agonists. Moreover, P50 is not a direct measure of na7 receptor target engagement. Thus, it is possible that even the highest tested AVL-3288 dose, $30 \mathrm{mg}$, was too low to engage the na7 receptor in this study. Finally, it is possible that the exclusion of smokers from the present and most prior trials of $\mathrm{na}_{7}$ receptor agonists could potentially bias against the inclusion of patients who have self-selected for nicotine responsiveness. In partial support of this, a recent trial of a $\mathrm{na}_{7}$ receptor agonist in smokers showed a trend level effect for negative symptoms [28].

In conclusion, the present results do not support AVL-3288 as a potential treatment for schizophrenia. Our results are consistent with most prior results for the $\mathrm{na}_{7}$ target, including a negative meta-analysis [14] and multiple failed Phase III studies. We are unaware of active studies using this mechanism. These results suggest caution for further, non-biomarker guided study of the $\mathrm{na}_{7}$ receptor as a therapeutic target in schizophrenia. Future work on the specificity of P50 as a na ${ }_{7}$ receptor biomarker could be warranted.

\section{FUNDING AND DISCLOSURE}

JTK reports having received consulting payments within the last 24 months from Krog \& Partners Incorporated, IQVIA, Alphasights, Charles River Associates, Putnam Associates, Piper Jaffray, MEDACorp, Simon Kucher, LifeSci Capital, ECRI Institute, Third Bridge, and BVF Partners. He has served on the Aristada Schizophrenia Advisory Board for Alkermes and the MedinCell Advisory Board. He has conducted clinical research supported by 
Table 2. Efficacy endpoint measures.

\begin{tabular}{|c|c|c|c|c|c|}
\hline & \multicolumn{3}{|c|}{ Change from Baseline ${ }^{a}$ Mean $\pm S E$} & \multicolumn{2}{|l|}{$p, d^{\mathrm{b}}$} \\
\hline \multicolumn{6}{|l|}{ RBANS } \\
\hline Total & $-0.0 \pm 2.2$ & $-0.6 \pm 2.2$ & $0.7 \pm 2.2$ & $0.81,-0.04$ & $0.75,0.05$ \\
\hline Immediate memory & $5.2 \pm 3.0$ & $2.9 \pm 2.9$ & $5.0 \pm 2.9$ & $0.54,-0.16$ & $0.94,-0.02$ \\
\hline Visuospatial/Constructional & $-3.5 \pm 1.9$ & $-1.8 \pm 1.9$ & $-2.2 \pm 1.9$ & $0.35,0.09$ & $0.48,0.07$ \\
\hline Delayed memory & $-2.3 \pm 3.0$ & $0.7 \pm 3.0$ & $1.7 \pm 3.0$ & $0.43,0.25$ & $0.29,0.33$ \\
\hline P50 ratio & $-0.4 \pm 0.1$ & $-0.3 \pm 0.1$ & $-0.3 \pm 0.1$ & $0.38,-0.10$ & $0.23,-0.13$ \\
\hline \multicolumn{6}{|l|}{ BPRS } \\
\hline Total & $-3.0 \pm 1.7$ & $-2.3 \pm 1.7$ & $-1.1 \pm 1.7$ & $0.69,-0.05$ & $0.24,-0.15$ \\
\hline Positive & $-1.1 \pm 0.7$ & $-0.8 \pm 0.7$ & $-0.7 \pm 0.7$ & $0.59,-0.06$ & $0.53,-0.07$ \\
\hline Affect & $-0.7 \pm 1.1$ & $-0.6 \pm 1.1$ & $0.2 \pm 1.1$ & $0.95,-0.01$ & $0.48,-0.11$ \\
\hline Alogia & $-0.6 \pm 0.8$ & $-2.0 \pm 0.8$ & $-0.3 \pm 0.8$ & $0.15,0.26$ & $0.76,-0.05$ \\
\hline Avolition & $-1.9 \pm 0.8$ & $-1.7 \pm 0.7$ & $-0.6 \pm 0.7$ & $0.79,-0.05$ & $0.06,-0.38$ \\
\hline Anhedonia & $-0.7 \pm 0.8$ & $-1.1 \pm 0.8$ & $-1.4 \pm 0.8$ & $0.60,0.09$ & $0.35,0.16$ \\
\hline Attention & $0.1 \pm 0.5$ & $-0.5 \pm 0.5$ & $-1.1 \pm 0.5$ & $0.28,0.16$ & $0.03,0.33$ \\
\hline \multicolumn{6}{|l|}{ RISE } \\
\hline Recognition accuracy & & & & $0.84,0.05$ & $0.76,-0.08$ \\
\hline Association accuracy & & & & $0.47,-0.22$ & $0.56,0.18$ \\
\hline Recognition PE & & & & $0.89,-0.05$ & $0.42,0.30$ \\
\hline Association PE & & & & $0.87,-0.05$ & $0.98,0.01$ \\
\hline
\end{tabular}

Table 3. Pharmacokinetics (ng/ml).

\begin{tabular}{|c|c|c|c|c|c|}
\hline \multirow[b]{2}{*}{ Time } & \multirow[b]{2}{*}{ Treatment } & \multicolumn{2}{|c|}{ Treatment } & \multicolumn{2}{|c|}{ Washout $^{\mathrm{a}}$} \\
\hline & & Mean & Std Dev & Mean & Std Dev \\
\hline \multirow[t]{3}{*}{1} & $30 \mathrm{mg}$ & 320.74 & 72.36 & 43.45 & 19.05 \\
\hline & $10 \mathrm{mg}$ & 154.34 & 29.36 & 16.09 & 7.18 \\
\hline & Placebo & 0.00 & 0.00 & 0.00 & 0.00 \\
\hline \multirow[t]{3}{*}{2} & $30 \mathrm{mg}$ & 355.62 & 63.39 & 70.43 & 10.53 \\
\hline & $10 \mathrm{mg}$ & 156.17 & 46.86 & 26.40 & 29.76 \\
\hline & Placebo & 27.01 & 17.06 & 21.46 & 16.87 \\
\hline \multirow[t]{3}{*}{3} & $30 \mathrm{mg}$ & 301.24 & 68.15 & 60.78 & 27.11 \\
\hline & $10 \mathrm{mg}$ & 162.72 & 82.25 & 68.86 & 22.86 \\
\hline & Placebo & 49.56 & 22.51 & 43.42 & 19.63 \\
\hline
\end{tabular}

${ }^{\mathrm{a}}$ Two subjects dropped from treatment time 3 placebo washout for out range values. Including these subjects: $50.9 \pm 20.9 \mathrm{ng} / \mathrm{ml}$.

the NIMH, Sunovion, the Stanley Foundation, Takeda, Taisho, Lundbeck, Boehringer Ingelheim, NeuroRX, Teva, and Lilly within the last 24 months. JTK a co-investigator on a study that receives lumeteperone and reimbursement for safety testing for an investigator-initiated research from Intra-Cellular Therapies Inc. He owns a small number of shares of common stock from GSK. DCJ reports having received consulting payments within the last 2 years from Pfizer, FORUM, Autifony, Glytech, SK Life Sci, Concert, and Cadence. He serves on a DSMB for Biogen. He holds intellectual property rights for use of NMDA modulators in treatment of neuropsychiatric disorders. He holds equity in Glytech, AASI, and NeuroRx, and serves on the advisory board of Promentis and NeuroRx. JAL does not accept any personal financial remuneration for consulting, speaking, or research activities from any pharmaceutical, biotechnology, or medical device companies. He receives funding and medication supplies for investigator-initiated research from Denovo, Taisho, and Cerevel, and company sponsored phase II, III, and IV studies from Alkermes, Sunovion, and Boehringer Ingelheim, which does not contribute to his compensation. He is a consultant or advisory board member of Intracellular Therapies, Takeda, Karuna, Pear Therapeutics, Systems-1, and Psychogenics for which he receives no remuneration. He is a paid consultant for Signant Health, a clinical research technology and services organization, and holds a patent from Repligen that yields no royalties. RF has served as a consultant to Minerva Pharmaceuticals. All other authors report no relevant conflicts. 
Table 4. Side effects reported.

\begin{tabular}{llll}
\hline & $10 \mathrm{mg}(\%)$ & $30 \mathrm{mg}(\%)$ & Placebo (\%) \\
\hline Nausea & 8.3 & 4.2 & 4.2 \\
Somnolence & 12.5 & 12.5 & 4.2 \\
Headache & 4.2 & 12.5 & 0 \\
Urinary urgency & 0 & 8.3 & 0 \\
Dizziness & 8.3 & 4.2 & 4.2 \\
Enuresis & 4.2 & 4.2 & 4.2 \\
Throat irritation & 0 & 4.2 & 0 \\
Diarrhea & 4.2 & 0 & 0 \\
Palpitations & 0 & 0 & 4.2 \\
Weakness & 0 & 0 & 4.2 \\
Increased appetite & 0 & 4.2 & 0 \\
Depression & 4.2 & 0 & 0 \\
Nasal irritation & 0 & 4.2 & 4.2 \\
Paresthesia & 4.2 & 0 & 4.2 \\
Abdominal discomfort & 0 & 4.2 & 0 \\
Vomiting & 4.2 & 0 & 0 \\
Urticaria & 0 & 0 & 4.2 \\
Flatulence & 0 & 4.2 & 0 \\
\hline
\end{tabular}

\section{ACKNOWLEDGEMENTS}

The authors acknowledge Jaimie Gowatsky for her assistance in collecting and analyzing EEG data. Funded by NIH U01 MH094247 to J.A.L. and J.T.K. (multiple PI). The authors report that there are no relevant conflicts with this report.

\section{AUTHOR CONTRIBUTIONS}

Dr Kantrowitz had full access to all of the data in the study and takes responsibility for the integrity of the data and the accuracy of the data analysis. All authors reviewed the final submission and gave final approval of the submitted version. Substantial contributions to conception and design: Kantrowitz, Javitt, Freedman, Sehatpour, Carlson, Wall, Choo, Kegeles and Lieberman. Acquisition, analysis, or interpretation of data: Kantrowitz, Javitt, Freedman, Sehatpour, Carlson, Kegeles, Wall, Vail, Sobeih, Choo, Grinband, Lieberman. Drafting of the manuscript: Kantrowitz, Wall, Choo, Grinband and Lieberman. Critical revision of the manuscript for important intellectual content: Kantrowitz, Javitt, Freedman, Sehatpour, Carlson, Wall, Choo, Grinband, Kegeles and Lieberman.

\section{ADDITIONAL INFORMATION}

Supplementary Information accompanies this paper at (https://doi.org/10.1038/ s41386-020-0628-9).

Publisher's note Springer Nature remains neutral with regard to jurisdictional claims in published maps and institutional affiliations.

\section{REFERENCES}

1. Kantrowitz JT. Managing negative symptoms of schizophrenia: how far have we come? CNS Drugs 2017;31:373-88.

2. Kurtz MM, Moberg JP, Ragland JD, Gur RC, Gur RE. Symptoms versus neurocognitive test performance as predictors of psychosocial status in schizophrenia: a 1- and 4-year prospective study. Schizophr Bull 2005;31:167-74.

3. Kirkpatrick B, Buchanan RW, Ross DE, Carpenter WT Jr. A separate disease within the syndrome of schizophrenia. Arch Gen Psychiatry. 2001:58:165-71.

4. Keefe RS, Haig GM, Marder SR, Harvey PD, Dunayevich E, Medalia A, et al. Report on ISCTM consensus meeting on clinical assessment of response to treatment of cognitive impairment in schizophrenia. Schizophr Bull 2016;42:19-33.

5. Green MF, Hellemann G, Horan WP, Lee J, Wynn JK. From perception to functional outcome in schizophrenia: modeling the role of ability and motivation. Arch Gen Psychiatry. 2012;69:1216-24.

6. Green MF, Horan WP, Lee J. Social cognition in schizophrenia. Nat Rev Neurosci. 2015;16:620-31.
7. Gold R, Butler PD, Revheim N, Leitman DI, Hansen JA, Gur RC, et al. Auditory emotion recognition impairments in Schizophrenia: Relationship to acoustic features and cognition. Am J Psychiatry. 2012;169:424-32.

8. Thomas ML, Green MF, Hellemann G, Sugar CA, Tarasenko M, Calkins ME, et al. Modeling deficits from early auditory information processing to psychosocial functioning in schizophrenia. JAMA Psychiatry. 2017;74:37-46.

9. Kapur $S$, Remington $G$. Dopamine $D(2)$ receptors and their role in atypical antipsychotic action: still necessary and may even be sufficient. Biol Psychiatry 2001;50:873-83.

10. Lieberman JA, Stroup TS, McEvoy JP, Swartz MS, Rosenheck RA, Perkins DO, et al. Effectiveness of antipsychotic drugs in patients with chronic schizophrenia. N. Engl J Med. 2005;353:1209-23.

11. Girgis RR, Zoghbi AW, Javitt DC, Lieberman JA. The past and future of novel, nondopamine-2 receptor therapeutics for schizophrenia: a critical and comprehensive review. J Psychiatr Res. 2018;108:57-83.

12. Hughes JR, Hatsukami DK, Mitchell JE, Dahlgren LA. Prevalence of smoking among psychiatric outpatients. Am J Psychiatry. 1986;143:993-7.

13. Olincy A, Young DA, Freedman R. Increased levels of the nicotine metabolite cotinine in schizophrenic smokers compared to other smokers. Biol Psychiatry 1997;42:1-5.

14. Lewis AS, van Schalkwyk GI, Bloch MH. Alpha-7 nicotinic agonists for cognitive deficits in neuropsychiatric disorders: a translational meta-analysis of rodent and human studies. Prog Neuropsychopharmacol Biol Psychiatry. 2017;75:45-53.

15. Freedman R. alpha7-nicotinic acetylcholine receptor agonists for cognitive enhancement in schizophrenia. Annu Rev Med. 2014;65:245-61.

16. Kantrowitz JT. N-methyl-d-aspartate-type glutamate receptor modulators and related medications for the enhancement of auditory system plasticity in schizophrenia. Schizophr Res 2019;207:70-9.

17. Preskorn SH, Gawryl M, Dgetluck N, Palfreyman M, Bauer LO, Hilt DC. Normalizing effects of EVP-6124, an Alpha-7 nicotinic partial agonist, on event-related potentials and cognition: a proof of concept, randomized trial in patients with schizophrenia. J Psychiatr Pract. 2014;20:12-24.

18. Huang M, Felix AR, Flood DG, Bhuvaneswaran C, Hilt D, Koenig G, et al. The novel alpha7 nicotinic acetylcholine receptor agonist EVP-6124 enhances dopamine, acetylcholine, and glutamate efflux in rat cortex and nucleus accumbens. Psychopharmacology. 2014;231:4541-51.

19. Maex R, Grinevich VP, Grinevich V, Budygin E, Bencherif M, Gutkin B. Understanding the role alpha7 nicotinic receptors play in dopamine efflux in nucleus accumbens. ACS Chem Neurosci. 2014;5:1032-40.

20. Olincy A, Harris JG, Johnson LL, Pender V, Kongs S, Allensworth D, et al. Proof-ofconcept trial of an alpha7 nicotinic agonist in schizophrenia. Arch Gen Psychiatry. 2006;63:630-8.

21. Winterer G, Gallinat J, Brinkmeyer J, Musso F, Kornhuber J, Thuerauf N, et al. Allosteric alpha-7 nicotinic receptor modulation and P50 sensory gating in schizophrenia: a proof-of-mechanism study. Neuropharmacology. 2013;64:197-204.

22. Keefe RS, Meltzer HA, Dgetluck N, Gawryl M, Koenig G, Moebius HJ, et al. Randomized, double-blind, placebo-controlled study of encenicline, an alpha7 nicotinic acetylcholine receptor agonist, as a treatment for cognitive impairment in schizophrenia. Neuropsychopharmacology 2015;40:3053-60.

23. Lieberman JA, Dunbar G, Segreti AC, Girgis RR, Seoane F, Beaver JS, et al. A randomized exploratory trial of an Alpha-7 nicotinic receptor agonist (TC-5619) for cognitive enhancement in schizophrenia. Neuropsychopharmacology 2013;38:968-75.

24. Haig GM, Bain EE, Robieson WZ, Baker JD, Othman AA. A Randomized trial to assess the efficacy and safety of ABT-126, a selective alpha7 nicotinic acetylcholine receptor agonist, in the treatment of cognitive impairment in schizophrenia. Am J Psychiatry. 2016;173:appiajp201515010093.

25. Umbricht D, Keefe RS, Murray S, Lowe DA, Porter R, Garibaldi G, et al. A randomized, placebo-controlled study investigating the nicotinic alpha7 agonist, RG3487, for cognitive deficits in schizophrenia. Neuropsychopharmacology 2014:39:1568-77.

26. Kem WR, Olincy A, Johnson L, Harris J, Wagner BD, Buchanan RW, et al. Pharmacokinetic limitations on effects of an Alpha7-nicotinic receptor agonist in schizophrenia: randomized trial with an extended-release formulation. Neuropsychopharmacology 2018;43:583-9.

27. Walling D, Marder SR, Kane J, Fleischhacker WW, Keefe RS, Hosford DA, et al. Phase 2 trial of an Alpha-7 nicotinic receptor agonist (TC-5619) in negative and cognitive symptoms of schizophrenia. Schizophr Bull 2016;42:335-43.

28. Haig GM, Wang D, Zhao J, Othman AA, Bain EE. Efficacy and Safety of the alpha7Nicotinic Acetylcholine Receptor Agonist ABT-126 in the Treatment of Cognitive Impairment Associated With Schizophrenia: Results From a Phase $2 \mathrm{~b}$ Randomized Controlled Study in Smokers. J Clin Psychiatry. 2018;79. https://doi. org/10.4088/JCP.16m11162. 
29. $\mathrm{Ng} \mathrm{HJ}$, Whittemore ER, Tran MB, Hogenkamp DJ, Broide RS, Johnstone TB, et al. Nootropic alpha7 nicotinic receptor allosteric modulator derived from GABAA receptor modulators. Proc Natl Acad Sci USA. 2007;104:8059-64.

30. Gee KW, Olincy A, Kanner R, Johnson L, Hogenkamp D, Harris J, et al. First in human trial of a type I positive allosteric modulator of alpha7-nicotinic acetylcholine receptors: pharmacokinetics, safety, and evidence for neurocognitive effect of AVL-3288. J Psychopharmacol 2017;31:434-41.

31. Grabb MC, Cross AJ, Potter WZ, McCracken JT. Derisking psychiatric drug development: the NIMH's fast fail program, a novel precompetitive model. J Clin Psychopharmacol. 2016;36:419-21.

32. Krystal AD, Pizzagalli DA, Mathew SJ, Sanacora G, Keefe R, Song A, et al. The first implementation of the NIMH FAST-FAIL approach to psychiatric drug development. Nat Rev Drug Discov. 2018;18:82-4.

33. Javitt DC, Carter CS, Krystal JH, Kantrowitz JT, Girgis RR, Kegeles LS, et al. Utility of imaging-based biomarkers for glutamate-targeted drug development in psychotic disorders: a randomized clinical trial. JAMA Psychiatry. 2018;75:11-9.

34. Kantrowitz JT, Swerdlow NR, Dunn W, Vinogradov S. Auditory system target engagement during plasticity-based interventions in schizophrenia: a focus on modulation of $\mathrm{N}$-methyl-D-aspartate-type glutamate receptor function. Biol Psychiatry. 2018;3:581-90.

35. Randolph C, Tierney MC, Mohr E, Chase TN. The repeatable battery for the assessment of neuropsychological status (RBANS): preliminary clinical validity. J Clin Exp Neuropsychol. 1998;20:310-9.

36. Freedman R, Adler LE, Waldo MC, Pachtman E, Franks RD. Neurophysiological evidence for a defect in inhibitory pathways in schizophrenia: comparison of medicated and drug-free patients. Biol Psychiatry 1983;18:537-51.

37. Overall JE, Gorham DE. The brief psychiatric rating scale. Psychol Rep. 1962;10:799-812.

38. Andreasen NC. The scale for the assessment of negative symptoms (SANS). lowa City: The University of lowa; 1984

39. Ragland JD, Blumenfeld RS, Ramsay IS, Yonelinas A, Yoon J, Solomon M, et al. Neural correlates of relational and item-specific encoding during working and long-term memory in schizophrenia. Neuroimage 2012;59:1719-26.

40. Ragland JD, Ranganath C, Barch DM, Gold JM, Haley B, MacDonald AW 3rd, et al Relational and item-specific encoding (RISE): task development and psychometric characteristics. Schizophr Bull. 2012;38:114-24.
41. Freedman R, Adler LE, Bickford P, Byerley W, Coon H, Cullum CM, et al. Schizophrenia and nicotinic receptors. Harv Rev Psychiatry. 1994;2:179-92.

42. Javitt DC, Freedman R. Sensory processing dysfunction in the personal experience and neuronal machinery of schizophrenia. Am J Psychiatry. 2015;172:17-31.

43. Leonard S, Freedman R. Genetics of chromosome 15q13-q14 in schizophrenia. Biol Psychiatry 2006;60:115-22.

44. Ragland JD, Ranganath C, Harms MP, Barch DM, Gold JM, Layher E, et al. Functional and neuroanatomic specificity of episodic memory dysfunction in schizophrenia: a functional magnetic resonance imaging study of the relational and item-specific encoding task. JAMA Psychiatry. 2015;72:909-16.

45. Gold JM, Queern C, lannone VN, Buchanan RW. Repeatable battery for the assessment of neuropsychological status as a screening test in schizophrenia I: sensitivity, reliability, and validity. Am J Psychiatry. 1999;156:1944-50.

46. Lee M, Sehatpour P, Dias EC, Silipo GS, Kantrowitz JT, Martinez AM, et al. A tale of two sites: differential impairment of frequency and duration mismatch negativity across a primarily inpatient versus a primarily outpatient site in schizophrenia. Schizophr Res 2018;191:10-7.

47. Potter D, Summerfelt A, Gold J, Buchanan RW. Review of clinical correlates of P50 sensory gating abnormalities in patients with schizophrenia. Schizophr Bull 2006;32:692-700.

48. Adler LE, Olincy A, Cawthra EM, McRae KA, Harris JG, Nagamoto HT, et al. Varied effects of atypical neuroleptics on P50 auditory gating in schizophrenia patients. Am J Psychiatry. 2004;161:1822-8.

49. Greenwood LM, Leung S, Michie PT, Green A, Nathan PJ, Fitzgerald P, et al. The effects of glycine on auditory mismatch negativity in schizophrenia. Schizophr Res 2018;191:61-9.

50. Kantrowitz JT, Epstein ML, Beggel O, Rohrig S, Lehrfeld JM, Revheim N, et al. Neurophysiological mechanisms of cortical plasticity impairments in schizophrenia and modulation by the NMDA receptor agonist D-serine. Brain 2016;139:3281-95.

51. Kantrowitz JT, Epstein ML, Lee M, Lehrfeld N, Nolan KA, Shope C, et al Improvement in mismatch negativity generation during $d$-serine treatment in schizophrenia: correlation with symptoms. Schizophr Res 2018;191:70-9.

52. Lavoie S, Murray MM, Deppen P, Knyazeva MG, Berk M, Boulat O, et al. Glutathione precursor, $\mathrm{N}$-acetyl-cysteine, improves mismatch negativity in schizophrenia patients. Neuropsychopharmacology 2008;33:2187-99. 